\title{
A vulnerable age group: the impact of cancer on the psychosocial well-being of young adult childhood cancer survivors
}

\author{
L. M. E. van $\operatorname{Erp}^{1} \cdot$ H. Maurice-Stam ${ }^{1}$ (1) • L. C. M. Kremer ${ }^{1,2} \cdot$ W. J. E. Tissing ${ }^{1,3} \cdot$ H. J. H. van der Pal ${ }^{1} \cdot$ A. C. H. de Vries ${ }^{1,4}$ • \\ M. M. van den Heuvel-Eibrink ${ }^{1,4} \cdot$ B. A. B. Versluys ${ }^{1,5} \cdot$ M. van der Heiden-van der Loo ${ }^{6} \cdot$ G. A. Huizinga ${ }^{1,3}$. \\ M. A. Grootenhuis ${ }^{1}$
}

Received: 17 September 2020 / Accepted: 19 January 2021 / Published online: 1 February 2021

(C) The Author(s) 2021

\begin{abstract}
Purpose This study aimed to increase our understanding of the psychosocial well-being of young adult childhood cancer survivors (YACCS) as well as the positive and negative impacts of cancer.

Methods YACCS (aged 18-30, diagnosed $\leq 18$, time since diagnosis $\geq 5$ years) cross-sectionally filled out the "Pediatric Quality of Life Inventory Young Adults" (PedsQL-YA), "Hospital Anxiety and Depression Scale" (HADS), and "Checklist Individual Strengths" (CIS-20R) to measure fatigue and survivor-specific "Impact of Cancer - Childhood Survivors" (IOC-CS), which measures the long-term impact of childhood cancer in several domains. Descriptive statistics (IOC-CS), logistic regression (HADS, CIS-20R), and ANOVA (PedsQL-YA, HADS, CIS-20R) were performed. Associations between positive and negative impacts of childhood cancer and psychosocial outcomes were examined with linear regression analyses.

Results YACCS $(N=151,61.6 \%$ female, mean age 24.1 \pm 3.6 , mean time since diagnosis $13.6 \pm 3.8)$ reported lower HRQOL $(-$ $.4 \leq d \leq-.5, p \leq .001)$ and more anxiety $(d=.4, p \leq .001)$, depression $(d=.4, p \leq .01)$, and fatigue $(.3 \leq d \leq .5, p \leq .001)$ than young adults from the general Dutch population. They were at an increased risk of experiencing (sub)clinical anxiety $(\mathrm{OR}=1.8$, $p=.017)$. YACCS reported more impact on scales representing a positive rather than negative impact of CC. Various domains of impact of childhood cancer were related to psychosocial outcomes, especially "Life Challenges" (HRQOL $\beta=-.18$, anxiety $\beta=.36$, depression $\beta=.29$ ) and "Body \& Health" (HRQOL $\beta=.27$, anxiety $\beta=-.25$, depression $\beta=-.26$, fatigue $\beta=-.47$ ). Conclusion YACCS are vulnerable to psychosocial difficulties, but they also experience positive long-term impacts of childhood cancer. Positive and negative impacts of childhood cancer were associated with psychosocial outcomes in YACCS. Screening of psychosocial outcomes and offering targeted interventions are necessary to optimize psychosocial long-term follow-up care for YACCS.
\end{abstract}

Keywords Childhood cancer · Young adults $\cdot$ Quality of life $\cdot$ Anxiety $\cdot$ Depression $\cdot$ Fatigue

H. Maurice-Stam

h.maurice-stam@prinsesmaximacentrum.nl

1 Princess Máxima Center for Pediatric Oncology, Heidelberglaan 25, 3584CS Utrecht, The Netherlands

2 Emma Children's Hospital, Amsterdam UMC, University of Amsterdam, Amsterdam, The Netherlands

3 Beatrix Children's Hospital/University of Groningen/University Medical Center Groningen, Groningen, The Netherlands

4 Sophia Children's Hospital/Erasmus Medical Center, Rotterdam, The Netherlands

5 Wilhelmina Children's Hospital/University Medical Center Utrecht, Utrecht, The Netherlands

6 Dutch Childhood Oncology Group, Utrecht, The Netherlands

\section{Background}

With the survival rate of childhood cancer rising, researchers and clinicians have an increased interest in the late effects of treatment. Long-term physical morbidity is high for childhood cancer survivors (CCS) [1, 2], as well as difficulty with psychological well-being [3-5].

Looking at the well-being of a patient population within the framework of a biopsychosocial model can be beneficial when studying the role of physical, psychological, and social factors [6]. In the biopsychosocial model, behavioral and social circumstances can influence the emergence, course, and experience of a disease, while the disease in itself influences psychological well-being and social relationships [6]. In 
accordance with the biopsychosocial model, knowledge of psychosocial late effects is crucial for improving life beyond childhood cancer. Attention to psychosocial late effects may be especially important for young adult childhood cancer survivors (YACCS) as young adulthood is a crucial life phase with many developmental challenges to overcome, e.g., relationships, sexuality, cognition, education, employment, and developing autonomy. A life-threatening disease such as cancer can disrupt this crucial development. This seems to be confirmed by research, as overall, YACCS reach fewer developmental milestones than young adults without a history of childhood cancer, which negatively affects their quality of life $[7,8]$. Both age-specific challenges and their potential disruption due to cancer can be seen within biological, psychological, and social domains, and can often present in multiple domains.

Contradicting findings have been reported on healthrelated quality of life (HRQOL) and well-being of CCS [3, 9-17]. Most (young) adult CCS did not report psychopathology, but survivors of central nervous system (CNS) tumors, those treated with cranial irradiation, and those with chronic health conditions had worse outcomes (distress, anxiety, depression, somatization, HRQOL, mental health dysfunction, fatigue, PTSD, unemployment, educational attainment) compared to reference groups $[3,4,12,13,17-23]$. While some studies indicate that fatigue is a problem among (YA)CCS $[18,20]$, other studies show that fatigue levels among CCS do not differ from reference groups or that clinical significance is questionable $[24,25]$. A recent review concluded that the prevalence of severe fatigue among CCS remains unclear, due in part to the heterogeneity of studies regarding inclusion criteria and samples as well as the questionnaires used to assess fatigue [26]. As fatigue has previously been linked to poor (HR)QOL $[5,18,27]$, it is crucial to investigate the incidence of fatigue in the Dutch population of YACCS and explore underlying mechanisms.

While almost all CCS studies include YACCS, most research among CCS does not differentiate between children, young adults, and older adults. Researching YACCS separately from older and younger CCS is crucial in order to understand the specific vulnerabilities and needs of young adults, which is necessary to provide CCS with targeted interventions that may help them bridge the gap between themselves and healthy peers early in their lives.

Besides the distinction of YACCS from both younger and older CCS, it is important to study YACCS separately from patients with and survivors of adolescent and young adult (AYA(-S)) cancer. While YACCS and AYA(-S) may be the same age, YACCS distinguish themselves regarding their diagnosis and treatment, a longer time since diagnosis, the presence of late effects of treatment, and a possible lack of knowledge about both their medical history and risk of late effects because of missed information during childhood. AYA cancer patients and YACCS are sometimes studied as one group, while results for the one group are not generalizable to the other $[28,29]$. Survivors of cancer in the AYA age report challenges (i.e., financial independence and protecting parents, cognitive decline in case of a brain tumor). These challenges differ from those reported by YACCS: identity formation, social isolation, health care transitions, and for those diagnosed with a brain tumor: cognitive deficits, limited career options, poor social skills. However, the two groups also express common challenges, such as physical appearance, fertility, late effects, social relationships, and changing priorities [30].

In order to increase our understanding of the experiences of and challenges for YACCS (aged 18-30, diagnosis at age $<$ 18 ), it is of great importance to look further than generic psychosocial constructs. Taking survivor-specific psychosocial factors into account can yield a broader perspective on the functioning of YACCS, which may help us tailor interventions to their needs. To gain broad insight into this functioning, the present study focused on generic psychosocial wellbeing, psychopathology, and survivor-specific constructs. First, to align with the previous literature, this study aimed to describe generic HRQOL, depression, anxiety, and fatigue in Dutch YACCS in comparison with reference groups. Secondly, the study aimed to describe the perceived impact of $\mathrm{CC}$, both positive and negative. By examining this survivor-specific construct, the authors aimed to deepen our insight into the experiences of YACCS. Finally, the study aimed to investigate the role of the survivor-specific construct of perceived impact in explaining generic psychosocial outcomes and psychopathology (HRQOL, depression, anxiety, and fatigue) in Dutch YACCS controlled for sociodemographic and medical characteristics.

\section{Methods}

A total of 400 YACCS were selected by a data manager of the Dutch LATER registry from 946 YACCS who met the eligibility criteria for the study (aged 18-30, diagnosed at age $<18$, $\geq 5$ years since diagnosis, treated at one of the four participating Dutch pediatric oncology centers, and no participation in the Dutch LATER study in the past 4 months) in the pseudonymized Dutch LATER registry. The selection was stratified in order to have an equal representation of men and women between the ages of 18 to 24 and 25 to 30 , as well as various groups based on age at diagnosis.

A total of 22 YACCS were excluded from the invitation for being recently deceased, having no known address, or living abroad. In 2018, the 378 remaining eligible YACCS were invited to fill out questionnaires on paper or online. Participants provided written informed consent and the 
Medical Ethical Committee of the University Hospital Utrecht reviewed this study (case number 18/256).

\section{Measures}

Medical characteristics Diagnosis and treatment data on the initial childhood cancer and recurrences, as well as aggregated data for non-participants, was collected from the Dutch LATER registry.

Sociodemographic characteristics Date of birth, gender, marital status, number of children, employment, and educational level (attained and current) were acquired.

HRQOL The Pediatric Quality of Life Inventory Young Adults (PedsQL-YA) measures HRQOL in four scales (Physical Functioning: 8 items, Cronbach's $\alpha=.86$; Emotional Functioning: 5 items, Cronbach's $\alpha=.84$; Social Functioning: 5 items, Cronbach's $\alpha=.85$; and Work/School Functioning: 5 items, Cronbach's $\alpha=.80$ ), a total scale (all 23 items, Cronbach's $\alpha=.92$ ), and a Psychosocial Summary Scale (PSY) combining emotional, social, and work/school functioning (15 items, Cronbach's $\alpha=.90$ ). Higher scores (range 0-100) indicate better HRQOL. The PedsQL-YA has good psychometric properties and a reference group of Dutch young adults is available [31].

Anxiety and depression The Hospital Anxiety and Depression Scale (HADS) measures anxiety and depression in separate scales and a total scale [32]. Participants are asked to respond to 14 statements, seven about anxiety (Cronbach's $\alpha=.88$ ) and seven about depression (Cronbach's $\alpha=.85$ ) by selecting one of four reactions specific to that statement. Higher scores on the HADS signal higher levels of anxiety and depression. Scale scores $\geq 8$ for anxiety and depression are considered (sub)clinical. The HADS has good psychometric properties [33] and a reference group of Dutch young adults is available [34].

Fatigue The Checklist Individual Strength (CIS-20R) is a valid measure of fatigue, consisting of four scales: Fatigue Severity ( 8 items, Cronbach's $\alpha=.79$ ), Concentration (5 items, Cronbach's $\alpha=.91$ ), Motivation (4 items, Cronbach's $\alpha=.82$ ), and Activity ( 3 items, Cronbach's $\alpha=.90$ ). In this study, the total score was not used, as its meaning is unclear [35]. Higher scores reflect more fatigue and fatigue-related impairment. The CIS-20R has good psychometric properties and a reference group of Dutch young adults is available [35].

Impact of cancer The IOC-CS is a survivor-specific questionnaire that measures perceived negative and positive impacts of CC [36]. It includes five positive impact scales (Socializing: 3 items, Cronbach's $\alpha=.59$; Talking with parents: 4 items, Cronbach's $\alpha=.92$; Body \& Health: 8 items, Cronbach's $\alpha=.80$; Health Literacy: 5 items, Cronbach's $\alpha=.71$; Personal Growth: 5 items, Cronbach's $\alpha=.71$ ) and six negative impact scales (Thinking \& Memory problems: 5 items, Cronbach's $\alpha=.76$; Sibling Concerns: 2 items, Cronbach's $\alpha=.69$; Life Challenges: 12 items, Cronbach's $\alpha=.86$; Relationship Concerns: 7 items, Cronbach's $\alpha=.65$ for partnered YACCS and .63 for non-partnered YACCS; Financial Problems: 3 items, Cronbach's $\alpha=.77$ ). Higher scores indicate more positive or negative impact. The IOCCS has been translated and back-translated into Dutch by Grootenhuis and Maurice-Stam in cooperation with the author of the original IOC-CS. The original version has good psychometric properties [36].

\section{Statistical analyses}

To compare characteristics of participants and non-participants, one-sample $t$ tests and binominal tests were used.

Differences between YACCS and the reference group were tested, controlled for age and sex, using logistic regression with odds ratio (HADS, CIS-20R) and ANOVA (PedsQLYA, HADS, CIS-20R) with Cohen's $d$ (.2 small, .5 medium, .8 large effect size) [37]. The IOC-CS scales were analyzed descriptively, using item scores and mean item scale scores.

Associations between positive and negative impacts of cancer (IOC-CS) and psychosocial outcomes were examined with multiple linear regression analyses. Separate models were estimated for PedsQL-YA total HRQOL, HADS anxiety, HADS depression, and CIS-20R Fatigue Severity, with positive and negative impacts of cancer (the IOC-CS mean item scale scores) as independent variables, while controlling for sociodemographic (sex and education) and medical (age at diagnosis, time since diagnosis, tumor type, recurrences, treatment) characteristics. All independent variables were entered in one step in all models. A significance level of .05 was used for all analyses based on two-sided tests. To adjust for multiple comparisons, a Bonferroni correction was applied per questionnaire for the PedsQL-YA $(.05 / 6=.008)$, HADS $(.05 / 3=.017)$, and CIS-20R $(.05 / 4=.013)$.

\section{Results}

\section{Sample characteristics}

A total of 151 YACCS (61.6\% female, mean age $24.1 \pm 3.6$, mean time since diagnosis $13.6 \pm 3.8)$ completed the questionnaire (response rate $=40 \%$ ). Participants were more often female and less likely to have received a bone marrow transplantation (BMT) than non-participants (Table 1). 
Table 1 Characteristics of participants and non-participants

\begin{tabular}{|c|c|c|c|c|c|}
\hline & \multicolumn{2}{|l|}{ Participants $(N \approx 151)$} & \multicolumn{2}{|c|}{ Non-participants $(N=223)$} & \multirow[b]{2}{*}{$p$ value } \\
\hline & Mean $\pm \mathrm{SD}$ (range) & $\%(N)$ & Mean \pm SD (range) & $\%(N)$ & \\
\hline \multicolumn{6}{|l|}{ Socio-demographic } \\
\hline Age (years) & $24.1 \pm 3.6(18-30)$ & & $24.0 \pm 3.4(18-30)$ & & \\
\hline \multirow[t]{2}{*}{ Sex (female) } & & $61.6(93)$ & & $40.8(90)$ & \\
\hline & & & & & $\begin{array}{l}.00- \\
0^{* *}\end{array}$ \\
\hline \multicolumn{6}{|c|}{ Marital/relationship status } \\
\hline Yes & & $51.0(75)$ & & & \\
\hline No & & $49.0(72)$ & & & \\
\hline \multicolumn{6}{|l|}{ Employment status } \\
\hline Paid occupation & & $70.9(105)$ & & & \\
\hline No paid occupation & & $29.1(43)$ & & & \\
\hline \multicolumn{6}{|l|}{ Educational attainment } \\
\hline Low & & $19.3(28)$ & & & \\
\hline Middle & & $48.3(70)$ & & & \\
\hline High & & $32.4(47)$ & & & \\
\hline \multicolumn{6}{|l|}{ Current education } \\
\hline Low & & $3.1(2)$ & & & \\
\hline Middle & & $27.7(18)$ & & & \\
\hline High & & $69.2(45)$ & & & \\
\hline \multicolumn{6}{|l|}{ Medical characteristics } \\
\hline Age at diagnosis & $10.5 \pm 4.5(.4-17)$ & & $10.6 \pm 4.5(0-18)$ & & \\
\hline \multirow[t]{2}{*}{ Time since diagnosis } & $13.6 \pm 3.8(6-27)$ & & $13.5 \pm 3.7(6-28)$ & & .756 \\
\hline & & & & & .652 \\
\hline \multicolumn{6}{|l|}{ Diagnosis } \\
\hline Hematologic cancers & & $66.9(101)$ & & $61.7(142)$ & \\
\hline \multirow{2}{*}{ CNS tumors } & & $8.6(13)$ & & $9.9(22)$ & .119 \\
\hline & & & & & .358 \\
\hline \multirow[t]{2}{*}{ Solid tumors } & & $24.5(37)$ & & $28.3(63)$ & \\
\hline & & & & & .173 \\
\hline \multirow{2}{*}{\multicolumn{6}{|c|}{ Treatment $t^{\mathrm{a}, \mathrm{b}}$}} \\
\hline & & & & & \\
\hline \multirow[t]{2}{*}{ Surgery (S) } & & $61.6(93)$ & & $63.7(142)$ & \\
\hline & & & & & .323 \\
\hline \multirow[t]{2}{*}{ Chemotherapy (CT) } & & 95.4 (144) & & 95.5 (213) & \\
\hline & & & & & .522 \\
\hline \multirow[t]{2}{*}{ Radiotherapy (RT) } & & $37.1(56)$ & & $35.0(78)$ & \\
\hline & & & & & .323 \\
\hline \multirow[t]{2}{*}{$\mathrm{SCT} / \mathrm{BMT}$} & & $7.3(11)$ & & $13.5(30)$ & \\
\hline & & & & & $\begin{array}{l}.01- \\
2^{*}\end{array}$ \\
\hline \multicolumn{6}{|l|}{ Treatment combinations ${ }^{\mathrm{b}}$} \\
\hline CT only & & $32.5(49)$ & & & \\
\hline $\mathrm{CT}+\mathrm{RT}$ & & $6.0(9)$ & & & \\
\hline $\mathrm{RT}+\mathrm{S}$ & & $4.6(7)$ & & & \\
\hline $\mathrm{CT}+\mathrm{S}$ & & $30.5(46)$ & & & \\
\hline $\mathrm{CT}+\mathrm{S}+\mathrm{RT}$ & & $26.5(40)$ & & & \\
\hline
\end{tabular}

${ }^{*} p<0.05 ; * * p<0.01$ (two-sided)

${ }^{a}$ More than one category possible

${ }^{\mathrm{b}}$ Treatments for primary tumor and (if applicable) recurrence(s)

\section{Psychosocial well-being of YACCS compared to the reference group}

YACCS reported lower HRQOL than the reference group on all PedsQL-YA scales $(-.4 \leq d \leq-.5)$ as well as higher levels of anxiety $(d=.4, p \leq .001)$ and depression $(d=.4, p=.019)$. YACCS were more likely to experience (sub)clinical anxiety than the reference group ( $29.8 \%$ vs. $18.8 \%, \mathrm{OR}=1.8)$. On the CIS-20R, YACCS reported increased Fatigue Severity $(d=.5)$ and worse Concentration $(d=.3)$ and were more likely 
to experience severe fatigue than the reference group (36.2\% vs. $20.8 \%, \mathrm{OR}=2.4$, Table 2).

\section{Positive and negative impacts of childhood cancer}

On scale level, most positive impact was reported on Socializing and least on Personal Growth. On item level, least positive impact was reported on "I have a special bond with others with cancer," "I have all the information I need," and "I know where to find information about cancer" (Table 3).

On scale level, most negative impact was reported on Thinking/Memory and least on Financial Problems. On item level, highest negative impact was reported on "It's hard to make decisions," "I worry about how my cancer affects my sibling," and "I feel like I missed out on life" (Table 3).

\section{Associations of impact of childhood cancer with psychosocial outcomes}

Two positive and two negative survivor-specific impact scales were associated with more than one psychosocial outcome (Table 4). More positive perception of Socializing was associated with better HRQOL $(\beta=.24)$ and less depression $(\beta=-$
.24). More positive perception of one's Body \& Health was related to better HRQOL $(\beta=.27)$ and less anxiety $(\beta=-.25)$, depression $(\beta=-.26)$, and fatigue $(\beta=-.47)$.

Regarding the negative impact scales, experiencing more Life Challenges was associated with lower HRQOL $(\beta=-$ $.18)$, more anxiety $(\beta=.36)$, and more depression $(\beta=.29)$. More Relationship Concerns were associated with lower HRQOL $(\beta=-.16)$ and more depression $(\beta=.19)$.

\section{Discussion}

This is one of the first studies to investigate survivor-specific psychosocial well-being in a large sample of YACCS specifically, and the first to do so in the Netherlands. This study shows that YACCS appear to be vulnerable to psychosocial difficulties. They reported worse HRQOL and more anxiety, depression, and fatigue than the reference group. Effect sizes ranged from small (depression) to large (fatigue severity). This is in accordance with findings of some earlier studies in CCS cohorts, which include YACCS but do not focus specifically on them $[3,5,13,15,38-40]$. Psychosocial well-being

Table 2 Psychosocial well-being of YACCS $(N \approx 151)$ versus reference groups

\begin{tabular}{|c|c|c|c|c|c|c|c|c|c|}
\hline & \multicolumn{4}{|c|}{ YACCS } & \multicolumn{3}{|c|}{ Reference group $^{\mathrm{a}}$} & \multirow[b]{2}{*}{ Cohen's $d$} & \multirow[b]{2}{*}{ OR } \\
\hline & $M$ & $\mathrm{SD}$ & $95 \% \mathrm{CI}$ & $\%(N)$ & $M$ & SD & $\%(N)$ & & \\
\hline PedsQL-YA (total score) & $77.7 *$ & 16.3 & {$[75.0 ; 80.3]$} & & 83.9 & 13.1 & & -.5 & \\
\hline Physical & $80.2 *$ & 19.7 & {$[77.0 ; 83.3]$} & & 87.1 & 16.0 & & -.4 & \\
\hline Emotional & $70.2 *$ & 21.2 & {$[66.8 ; 73.6]$} & & 77.2 & 18.0 & & -.4 & \\
\hline Social & $82.1 *$ & 20.0 & {$[78.9 ; 85.3]$} & & 87.2 & 14.5 & & -.4 & \\
\hline Work/school & $76.8 *$ & 19.1 & {$[73.7 ; 79.8]$} & & 82.3 & 15.7 & & -.4 & \\
\hline Psychosocial & $76.3 *$ & 16.9 & {$[73.6 ; 79.0]$} & & 82.2 & 13.7 & & -.4 & \\
\hline HADS (total score) & $9.4 *$ & 6.9 & {$[8.3 ; 10.5]$} & & 7.0 & 5.7 & & .4 & \\
\hline Anxiety & $5.9 *$ & 4.3 & {$[5.3 ; 6.6]$} & & 4.4 & 3.5 & & .4 & \\
\hline Depression & $3.5^{*}$ & 3.5 & {$[2.9 ; 4.1]$} & & 2.6 & 2.8 & & .3 & \\
\hline (Sub)clinical anxiety $(\geq 8)$ & & & {$[.2 ; .4]$} & $30.2(45)$ & & & $18.8(42)$ & & $1.8^{*}$ \\
\hline (Sub)clinical depression $(\geq 8)$ & & & {$[.1 ; .2]$} & $12.8(19)$ & & & $7.6(17)$ & & 1.7 \\
\hline \multicolumn{10}{|l|}{ CIS-20R } \\
\hline Fatigue Severity & $30.6^{*}$ & 9.9 & {$[29.0 ; 32.2]$} & & 25.2 & 10.4 & & .5 & \\
\hline Concentration & $15.8^{*}$ & 7.8 & {$[14.6 ; 17.1]$} & & 13.8 & 6.3 & & .3 & \\
\hline Motivation & 10.6 & 5.1 & {$[9.8 ; 11.5]$} & & 11.1 & 4.7 & & -.1 & \\
\hline Activity & 9.9 & 5.1 & {$[9.1 ; 10.7]$} & & 9.7 & 4.6 & & .1 & \\
\hline Severe fatigue $(\geq 35)$ & & & {$[.3 ; .4]$} & $36.2(54)$ & & & $20.8(55)$ & & $2.4^{*}$ \\
\hline
\end{tabular}

$M$ mean, $S D$ standard deviation, $O R$ odds ratio

PedsQL-YA: $* p<.008$ (two-sided)

HADS: $* p<.017$ (two-sided)

CIS-20R: $* p<.013$ (two-sided)

${ }^{a}$ PedsQL-YA $N=649 ;$ HADS $N=224$; CIS-20-R $N=264$ 
Table 3 Perceived impact of cancer according to the IOC-CS

$N$

Positive impact scales

Socializing

Do not feel left out of friends' lives

Do not avoid social activities

Make friends easily

Talking with Parents

Mom comfortable talking about cancer

Can talk with dad about cancer

Can talk with mom about cancer

Dad comfortable talking about cancer

Body \& Health

Eat healthy diet

Lead healthy life

Self-confident

Feel in control

Healthy as those w/o cancer

Believe I'm attractive

Like my body

Exercise

Health Literacy

Easy to talk to doctor about cancer

Know who to see for med problems

Feel doctor knows cancer effects

Know where to find cancer info

Have all cancer info I need

Personal Growth

More mature than those without cancer

Cancer part of self

Learned about self

Good things came from cancer

Special bond with others with cancer

Negative impact scales

Thinking/Memory

Hard to make decisions

Hard time thinking

Trouble w/long-term memory

Hard to learn

Trouble w/short-term memory

Sibling Concerns

Worry how cancer affected siblings

Sibling had problems related to my cancer

Life Challenges

Missed out on life

Wonder why I got cancer

Worry about health

Wonder why I survived

Want to forget cancer

Afraid to die

Unsure about future
149

149

147

149

150

148

147

148

146

151

151

151

151

151

151

151

151

151

151

151

151

150

151

150

150

151

150

150

150

145

150

150

150

150

150

150

141

142

141

151

149

151

150

151

150

150

150
$M^{\mathrm{a}}$

SD

4.0

4.3

4.2

3.4

3.5

3.5

3.5

3.5

3.4

3.5

3.9

3.9

3.6

3.5

3.4

3.2

3.2

3.1

3.3

4.1

4.0

3.1

2.8

2.6

2.8

3.2

3.1

3.1

2.9

1.9

2.5

3.1

2.6

2.5

2.3

2.2

2.3

2.8

1.8

2.1

2.8

2.5

2.4

2.4

2.2

2.1

2.1
.91

1.1

1.1

1.2

1.3

1.3

1.4 
Table 3 (continued)

\begin{tabular}{|c|c|c|c|}
\hline & $N$ & $M^{\mathrm{a}}$ & SD \\
\hline Worry I will die at young age & 150 & 2.0 & 1.3 \\
\hline Cancer controls my life & 148 & 2.0 & 1.2 \\
\hline Angry about cancer & 151 & 1.9 & 1.2 \\
\hline Time is running out & 149 & 1.5 & 1.0 \\
\hline Something I did caused cancer & 151 & 1.5 & 1.1 \\
\hline Relationship Concerns total & 150 & 1.8 & .8 \\
\hline Partnered & 77 & 1.7 & .7 \\
\hline Hard to talk to partner about health problem & 77 & 2.1 & .9 \\
\hline Worry partner will leave if cancer returns & 77 & 1.7 & 1.2 \\
\hline Worry about having sex with partner & 77 & 1.4 & .7 \\
\hline Non-partnered & 73 & 1.9 & .8 \\
\hline Worry about telling potential partner about fertility & 73 & 2.2 & 1.3 \\
\hline Worry about having no relationship & 73 & 2.2 & 1.2 \\
\hline Worry about having sex & 73 & 1.8 & 1.2 \\
\hline Worry about telling potential partner about cancer & 73 & 1.6 & .9 \\
\hline Financial Problems & 147 & 1.3 & .5 \\
\hline Trouble getting assistance/services & 147 & 1.5 & 1.0 \\
\hline Parents financial problems from cancer & 147 & 1.2 & 6 \\
\hline Financial problems from cancer & 147 & 1.1 & 6 \\
\hline
\end{tabular}

"Mean item scores: 1 = "none at all"; 2 = "a little bit"; 3 = "somewhat"; 4 = "quite a bit"; 5 = "very much"

similar to that of the general population has also been reported [9-12, 16, 19, 41, 42].

Our study illuminates the experiences of YACCS regarding impact of childhood cancer. The IOC-CS scale scores in this study found more impact on concepts representing positive impact (Socializing, Talking with parents, Body \& Health) than on concepts representing negative impact (Thinking \& Memory problems, Life Challenges). This finding is in line with a study among CCS in the USA [36]. Survivors may have a tendency to minimize the effect of the negative aspects of their cancer experience on their current lives while maximizing the positive aspects [43, 44].

\section{Clinical implications}

Based on our findings that YACCS report worse HRQOL and more anxiety, depression, and fatigue, the authors recommend routine psychosocial screening during long-term follow-up (LTFU). LTFU clinics need to have mechanisms, e.g., inhouse psychologists or adequate referral options, in place to follow-up when screening results call for psychosocial support for a YACCS. These recommendations are in line with the existing standards of care [45]. Fatigue warrants special attention as a known late effect of treatment. In a large cohort, fatigue, as well as poor sleep and vitality, was shown to be associated with survivors' neurocognitive functioning independent of other well-known risk factors (e.g., cranial radiation and female gender) [46], making it an important topic to be addressed by physicians, nurses, and psychosocial care providers during LTFU.

YACCS' scores on some specific items of the IOC-CS yield important insights for psychosocial care. Item scores on Health Literacy of the IOC-CS showed that YACCS perceived a lack of information about the long-term effects of childhood cancer as well as a lack of the skills required to obtain such information. Information provision and supporting YACCS' health literacy skills are important tasks for health care providers during LTFU. YACCS have previously reported problems with autonomy development [7] and gaining independence from their parents [47, 48], as well as with lacking information [49]. This disruption in crucial developmental areas during young adulthood could have consequences for their psychosocial well-being as well as their selfmanagement in adulthood. YACCS may therefore benefit from a focus on patient empowerment during their LTFU.

Positive and negative impacts of childhood cancer were more strongly associated with psychosocial well-being than sociodemographic and medical characteristics (see Table 4), which Zebrack [44] also found. These findings align with earlier studies that showed the role of self-reported functional limitations and health beliefs in relation to HRQOL of CCS $[42,50]$ as well as a strong association between fatigue and emotional distress and functional limitations in survivors of childhood Hodgkin's lymphoma [51]. YACCS' perception of their Body \& Health, Life Challenges, Socializing, and Relationships need special attention during LTFU based on 


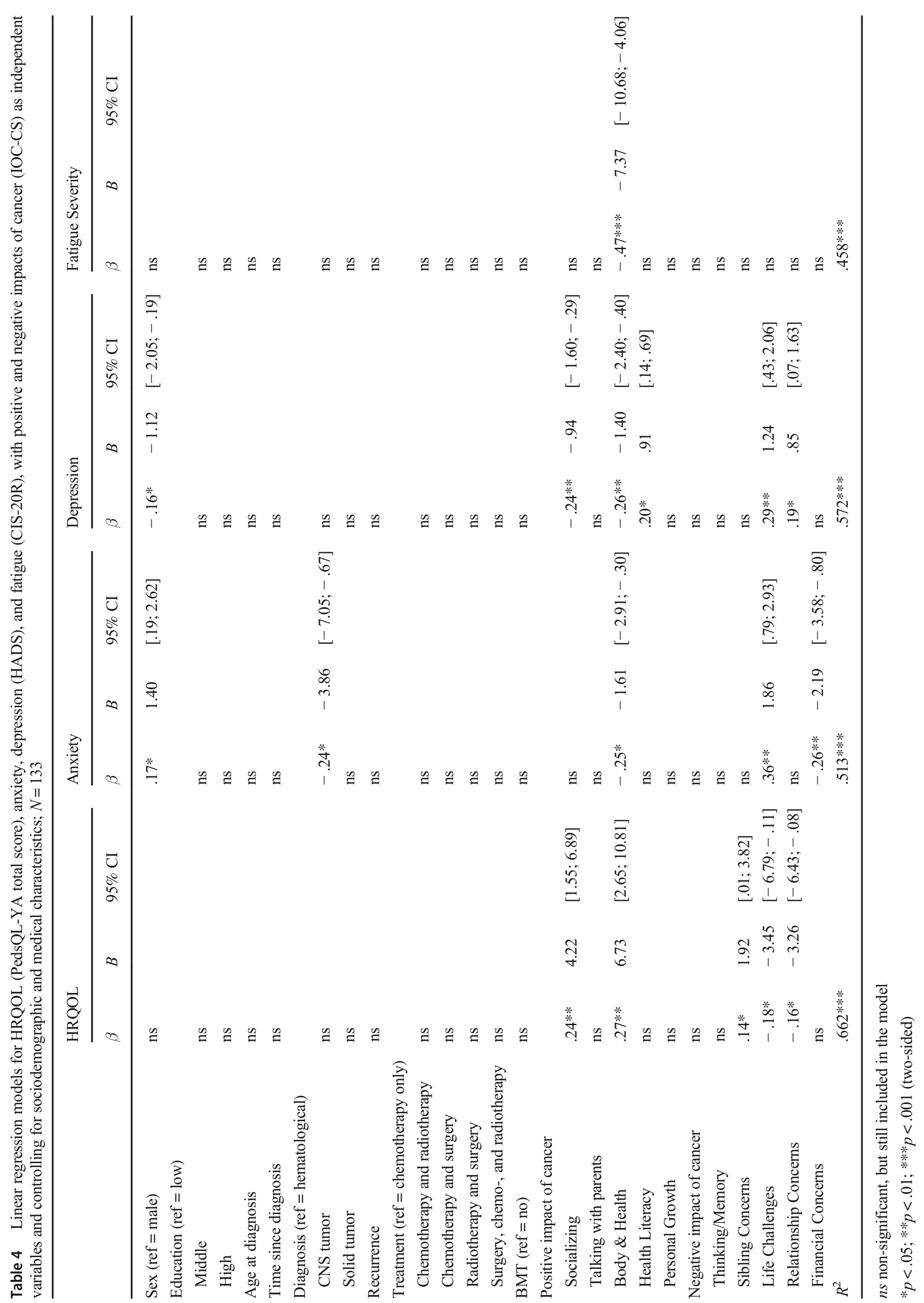


their associations with psychosocial outcomes found in this study. While Thinking and Memory problems had the highest perceived negative impact, they were not associated with the psychosocial outcomes in our sample of YACCS. This finding is worth further exploration, because previous literature suggests that neuropsychological late effects of childhood cancer are common and can be severe [52, 53]. Furthermore, previous results showed that neuropsychological late effects can potentially influence psychosocial outcomes such as HRQOL [54-56] and fatigue [46].

Regarding the high percentages of explained variance in our models, it is arguable that perceived impact of childhood cancer and generic psychosocial outcomes are overlapping constructs. Furthermore, it is plausible to assume that the associations between impact of childhood cancer and psychosocial well-being are bidirectional. Accordingly, interventions directed at the perceived impact of cancer, e.g., cognitive behavioral therapy (CBT), could also improve psychosocial well-being, and vice versa. The value of understanding perceived impact of childhood cancer is that it may help us tailor interventions specifically to YACCS by focusing on maladaptive cognitions related to the impact of childhood cancer in young adulthood. In line with this understanding, the psychosocial department at the Princess Máxima Center has recently added an e-health module for YACCS to our CBT-based program "Op Koers" [57] and conducted a pilot. The initial results were promising. The authors' next research efforts will focus on evaluating the intervention in order to provide this vulnerable group with an evidence-based psychosocial program.

\section{Study limitations}

This study has some limitations that need to be taken into account. First, there was a $40 \%$ response rate, though nonparticipants hardly differed from participants. Compared to other studies from the Dutch LATER cohort, survivors of CNS tumors seem to be underrepresented in our study [58]. This may complicate the generalization of our study's findings to all Dutch YACCS. Our within-group models are probably unaffected by the response rate. Second, because of the cross-sectional nature of this study, it was impossible to distinguish between cause and effect within the relationships found in our sample. Third, educational attainment was included as a predictor in our regression models because this variable was most indicative of socioeconomic status (SES) out of the data available. However, educational attainment has previously been found to be an outcome of childhood cancer history in the literature $[23,47]$. Fourth, the presence of chronic health problems due to the disease were not taken into account in the regression models because we did not have access to data on disease burden.

Lastly, a limited number of independent variables were entered into our linear regression model. The aim of this study was to investigate the role of the positive and negative impact of cancer as opposed to creating the most fitting model to explain psychosocial outcomes in YACCS.

\section{Conclusion}

YACCS are a vulnerable group. That said, they reported more positive than negative impacts of CC. The perceived impact of $\mathrm{CC}$, positive as well as negative, was more strongly associated with psychosocial well-being than sociodemographic and medical characteristics. Addressing perceived impact of childhood cancer may be the gateway for targeting psychosocial interventions in pediatric oncology. Routine psychosocial screening of YACCS for HRQOL, anxiety, depression, and fatigue is recommended. Psychosocial interventions should be offered to YACCS proactively and focus primarily on perceived impact of cancer.

Acknowledgements We further thank prof. Ad Vingerhoets for providing the HADS reference group and prof. Hans Knoop for providing the CIS-20R reference group.

Author contribution Loes van Erp: data curation, formal analysis, validation, investigation, methodology, project administration, writing. Heleen Maurice-Stam: conceptualization, methodology, formal analysis, data curation, validation, writing (review/editing), supervision, funding acquisition. Leontien Kremer, Margriet van der Heiden-van der Loo: methodology, writing (review/editing), resources. Wim Tissing, Heleen van der Pal, Andrica de Vries, Marry van den Heuvel-Eibrink, Birgitta Versluys: writing (review/editing), resources. Gea Huizinga, Martha Grootenhuis: conceptualization, writing (review/editing), supervision, funding acquisition

Funding This research was funded by KiKa (\#293).

Data availability The datasets generated during and/or analyzed during the current study are available from the corresponding author on reasonable request.

\section{Declarations}

Ethics approval and consent to participate This study was reviewed by Medical Ethical Committee of the University Hospital Utrecht (case number 18/256). Informed consent was obtained from all individual participants included in the study.

Conflict of interest The authors declare no competing interests.

Open Access This article is licensed under a Creative Commons Attribution 4.0 International License, which permits use, sharing, adaptation, distribution and reproduction in any medium or format, as long as you give appropriate credit to the original author(s) and the source, provide a link to the Creative Commons licence, and indicate if changes were made. The images or other third party material in this article are included in the article's Creative Commons licence, unless indicated otherwise in a credit line to the material. If material is not included in the article's Creative Commons licence and your intended use is not permitted by statutory regulation or exceeds the permitted use, you will need to obtain 
permission directly from the copyright holder. To view a copy of this licence, visit http://creativecommons.org/licenses/by/4.0/.

\section{References}

1. Oeffinger KC, Mertens AC, Sklar CA, Kawashima T, Hudson MM, Meadows AT, Friedman DL, Marina N, Hobbie W, KadanLottick NS, Schwartz CL, Leisenring W, Robison LL (2006) Chronic health conditions in adult survivors of childhood cancer. N Engl J Med 355(15):1572-1582

2. Bhakta N, Liu Q, Ness KK, Baassiri M, Eissa H, Yeo F, Chemaitilly W, Ehrhardt MJ, Bass J, Bishop MW, Shelton K, Lu L, Huang S, Li Z, Caron E, Lanctot J, Howell C, Folse T, Joshi V, Green DM, Mulrooney DA, Armstrong GT, Krull KR, Brinkman TM, Khan RB, Srivastava DK, Hudson MM, Yasui Y, Robison LL (2017) The cumulative burden of surviving childhood cancer: an initial report from the St Jude Lifetime Cohort Study (SJLIFE). Lancet. 390(10112):2569-2582

3. Huang IC, Brinkman TM, Armstrong GT, Leisenring W, Robison LL, Krull KR (2017) Emotional distress impacts quality of life evaluation: a report from the Childhood Cancer Survivor Study. J Cancer Surviv 11(3):309-319

4. Fidler MM, Ziff OJ, Wang S, Cave J, Janardhanan P, Winter DL et al (2015) Aspects of mental health dysfunction among survivors of childhood cancer. Br J Cancer 113(7):1121-1132

5. Kanellopoulos A, Hamre HM, Dahl AA, Fossa SD, Ruud E (2013) Factors associated with poor quality of life in survivors of childhood acute lymphoblastic leukemia and lymphoma. Pediatr Blood Cancer 60(5):849-855

6. Engel GL (1977) The need for a new medical model: a challenge for biomedicine. Science. 196(4286):129-136

7. Stam H, Grootenhuis MA, Last BF (2005) The course of life of survivors of childhood cancer. Psychooncology. 14(3):227-238

8. Maurice-Stam H, Grootenhuis MA, Caron HN, Last BF (2007) Course of life of survivors of childhood cancer is related to quality of life in young adulthood. J Psychosoc Oncol 25(3):43-58

9. Bitsko MJ, Cohen D, Dillon R, Harvey J, Krull K, Klosky JL (2016) Psychosocial late effects in pediatric cancer survivors: a report from the Children's Oncology Group. Pediatr Blood Cancer 63(2):337-343

10. Nathan PC, Ness KK, Greenberg ML, Hudson M, Wolden S, Davidoff A, Laverdiere C, Mertens A, Whitton J, Robison LL, Zeltzer L, Gurney JG (2007) Health-related quality of life in adult survivors of childhood Wilms tumor or neuroblastoma: a report from the childhood cancer survivor study. Pediatr Blood Cancer 49(5):704-715

11. Reulen RC, Winter DL, Lancashire ER, Zeegers MP, Jenney ME, Walters SJ, Jenkinson C, Hawkins MM (2007) Health-status of adult survivors of childhood cancer: a large-scale population-based study from the British Childhood Cancer Survivor Study. Int J Cancer 121(3):633-640

12. Zebrack BJ, Zeltzer LK, Whitton J, Mertens AC, Odom L, Berkow R, Robison LL (2002) Psychological outcomes in long-term survivors of childhood leukemia, Hodgkin's disease, and non-Hodgkin's lymphoma: a report from the Childhood Cancer Survivor Study. Pediatrics. 110(1 Pt 1):42-52

13. Rueegg CS, Gianinazzi ME, Rischewski J, Beck Popovic M, von der Weid NX, Michel G, Kuehni CE (2013) Health-related quality of life in survivors of childhood cancer: the role of chronic health problems. J Cancer Surviv 7(4):511-522

14. Stam H, Grootenhuis MA, Caron HN, Last BF (2006) Quality of life and current coping in young adult survivors of childhood cancer: positive expectations about the further course of the disease were correlated with better quality of life. Psychooncology. 15(1): $31-43$

15. Nies M, Klein Hesselink MS, Huizinga GA, Sulkers E, Brouwers AH, Burgerhof JGM, van Dam EWCM, Havekes B, van den Heuvel-Eibrink MM, Corssmit EPM, Kremer LCM, Netea-Maier RT, van der Pal HJH, Peeters RP, Plukker JTM, Ronckers CM, van Santen HM, Tissing WJE, Links TP, Bocca G (2017) Long-term quality of life in adult survivors of pediatric differentiated thyroid carcinoma. J Clin Endocrinol Metab 102(4):1218-1226

16. van der Geest IM, van Dorp W, Hop WC, Neggers SJ, de Vries AC, Pieters R et al (2013) Emotional distress in 652 Dutch very longterm survivors of childhood cancer, using the hospital anxiety and depression scale (HADS). J Pediatr Hematol Oncol 35(7):525-529

17. Zeltzer LK, Lu Q, Leisenring W, Tsao JC, Recklitis C, Armstrong G et al (2008) Psychosocial outcomes and health-related quality of life in adult childhood cancer survivors: a report from the childhood cancer survivor study. Cancer Epidemiol Biomark Prev 17(2):435446

18. Jóhannsdóttir IMR, Hjermstad MJ, Torbjorn M, Wesenberg F, Hjorth L, Schroder H et al (2012) Increased prevalence of chronic fatigue among survivors of childhood cancers: a population-based study. Pediatr Blood Cancer 58(3):415-420

19. Kamibeppu K, Sato I, Honda M, Ozono S, Sakamoto N, Iwai T, Okamura J, Asami K, Maeda N, Inada H, Kakee N, Horibe K, Ishida Y (2010) Mental health among young adult survivors of childhood cancer and their siblings including posttraumatic growth. J Cancer Surviv 4(4):303-312

20. Zeltzer LK, Recklitis C, Buchbinder D, Zebrack B, Casillas J, Tsao JC et al (2009) Psychological status in childhood cancer survivors: a report from the Childhood Cancer Survivor Study. J Clin Oncol 27(14):2396-2404

21. Meeske KA, Ruccione K, Globe DR, Stuber ML (2001) Posttraumatic stress, quality of life, and psychological distress in young adult survivors of childhood cancer. Oncol Nurs Forum 28(3):481-489

22. Mort S, Salantera S, Matomaki J, Salmi TT, Lahteenmaki PM (2011) Cancer related factors do not explain the quality of life scores for childhood cancer survivors analysed with two different generic HRQL instruments. Cancer Epidemiol 35(2):202-210

23. Gurney JG, Krull KR, Kadan-Lottick N, Nicholson HS, Nathan PC, Zebrack B, Tersak JM, Ness KK (2009) Social outcomes in the Childhood Cancer Survivor Study cohort. J Clin Oncol 27(14): 2390-2395

24. Langeveld NE, Grootenhuis MA, Voute PA, de Haan RJ, van den Bos C (2003) No excess fatigue in young adult survivors of childhood cancer. Eur J Cancer 39(2):204-214

25. Mulrooney DA, Ness KK, Neglia JP, Whitton JA, Green DM, Zeltzer LK, Robison LL, Mertens AC (2008) Fatigue and sleep disturbance in adult survivors of childhood cancer: a report from the childhood cancer survivor study (CCSS). Sleep. 31(2):271-281

26. van Deuren S, Boonstra A, van Dulmen-den Broeder E, Blijlevens N, Knoop H, Loonen J (2020) Severe fatigue after treatment for childhood cancer. Cochrane Database Syst Rev 3:CD012681

27. Meeske KA, Patel SK, Palmer SN, Nelson MB, Parow AM (2007) Factors associated with health-related quality of life in pediatric cancer survivors. Pediatr Blood Cancer 49(3):298-305

28. Gunnes MW, Lie RT, Bjorge T, Syse A, Ruud E, Wesenberg F et al (2016) Economic independence in survivors of cancer diagnosed at a young age: a Norwegian national cohort study. Cancer. 122(24): 3873-3882

29. Brewster DH, Clark D, Hopkins L, Bauer J, Wild SH, Edgar AB, Wallace WH (2014) Subsequent hospitalisation experience of 5year survivors of childhood, adolescent, and young adult cancer in Scotland: a population based, retrospective cohort study. Br J Cancer 110(5):1342-1350 
30. D'Agostino NM, Edelstein K (2013) Psychosocial challenges and resource needs of young adult cancer survivors: implications for program development. J Psychosoc Oncol 31(6):585-600

31. Limperg PF, Haverman L, van Oers HA, van Rossum MA, Maurice-Stam H, Grootenhuis MA (2014) Health related quality of life in Dutch young adults: psychometric properties of the PedsQL generic core scales young adult version. Health Qual Life Outcomes 12(9):9

32. Snaith RP (2003) The Hospital Anxiety And Depression Scale. Health Qual Life Outcomes 1:29

33. Spinhoven P, Ormel J, Sloekers PP, Kempen GI, Speckens AE, Van Hemert AM (1997) A validation study of the Hospital Anxiety and Depression Scale (HADS) in different groups of Dutch subjects. Psychol Med 27(2):363-370

34. CentER Data 2007 [Available from: https://www.centerdata.nl

35. Worm-Smeitink M, Gielissen M, Bloot L, van Laarhoven HWM, van Engelen BGM, van Riel P, Bleijenberg G, Nikolaus S, Knoop $\mathrm{H}$ (2017) The assessment of fatigue: psychometric qualities and norms for the Checklist individual strength. J Psychosom Res 98: $40-46$

36. Zebrack BJ, Donohue JE, Gurney JG, Chesler MA, Bhatia S, Landier W (2010) Psychometric evaluation of the Impact of Cancer (IOC-CS) scale for young adult survivors of childhood cancer. Qual Life Res 19(2):207-218

37. Cohen J (1988) Statistical power analysis for the behavioral sciences. Second edition ed. Lawrence Erlbaum Associates, Inc., Hillsdale

38. Servitzoglou M, Papadatou D, Tsiantis I, Vasilatou-Kosmidis H (2009) Quality of life of adolescent and young adult survivors of childhood cancer. J Pediatr Nurs 24(5):415-422

39. Blaauwbroek R, Stant AD, Groenier KH, Kamps WA, Meyboom B, Postma A (2007) Health-related quality of life and adverse late effects in adult (very) long-term childhood cancer survivors. Eur J Cancer 43(1):122-130

40. Langeveld NE, Grootenhuis MA, Voute PA, de Haan RJ, van den Bos C (2004) Quality of life, self-esteem and worries in young adult survivors of childhood cancer. Psychooncology. 13(12):867-881

41. Sundberg KK, Doukkali E, Lampic C, Eriksson LE, Arvidson J, Wettergren L (2010) Long-term survivors of childhood cancer report quality of life and health status in parity with a comparison group. Pediatr Blood Cancer 55(2):337-343

42. Kazak AE, Derosa BW, Schwartz LA, Hobbie W, Carlson C, Ittenbach RF et al (2010) Psychological outcomes and health beliefs in adolescent and young adult survivors of childhood cancer and controls. J Clin Oncol 28(12):2002-2007

43. Wilson AE, Ross M (2001) From chump to champ: people's appraisals of their earlier and present selves. J Pers Soc Psychol 80(4): 572-584

44. Zebrack BJ, Landier W (2011) The perceived impact of cancer on quality of life for post-treatment survivors of childhood cancer. Qual Life Res 20(10):1595-1608

45. Wiener L, Kazak AE, Noll RB, Patenaude AF, Kupst MJ (2015) Standards for the psychosocial care of children with cancer and their families: an introduction to the special issue. Pediatr Blood Cancer 62(Suppl 5):S419-S424

46. Clanton NR, Klosky JL, Li C, Jain N, Srivastava DK, Mulrooney D, Zeltzer L, Stovall M, Robison LL, Krull KR (2011) Fatigue, vitality, sleep, and neurocognitive functioning in adult survivors of childhood cancer: a report from the Childhood Cancer Survivor Study. Cancer. 117(11):2559-2568
47. Langeveld NE, Ubbink MC, Last BF, Grootenhuis MA, Voute PA, De Haan RJ (2003) Educational achievement, employment and living situation in long-term young adult survivors of childhood cancer in the Netherlands. Psychooncology. 12(3):213-225

48. Smits-Seemann RR, Yi J, Tian T, Warner EL, Kirchhoff AC (2017) A qualitative inquiry of childhood and adolescent cancer survivors' perspectives of independence. J Adolesc Young Adult Oncol 6(1): 91-95

49. Zebrack BJ, Eshelman DA, Hudson MM, Mertens AC, Cotter KL, Foster BM, Loftis L, Sozio M, Oeffinger KC (2004) Health care for childhood cancer survivors: insights and perspectives from a Delphi panel of young adult survivors of childhood cancer. Cancer. 100(4): $843-850$

50. Ness KK, Gurney JG, Zeltzer LK, Leisenring W, Mulrooney DA, Nathan PC, Robison LL, Mertens AC (2008) The impact of limitations in physical, executive, and emotional function on healthrelated quality of life among adult survivors of childhood cancer: a report from the Childhood Cancer Survivor Study. Arch Phys Med Rehabil 89(1):128-136

51. Rach AM, Crabtree VM, Brinkman TM, Zeltzer L, Marchak JG, Srivastava D et al (2017) Predictors of fatigue and poor sleep in adult survivors of childhood Hodgkin's lymphoma: a report from the Childhood Cancer Survivor Study. J Cancer Surviv 11(2):256263

52. Butler RW, Haser JK (2006) Neurocognitive effects of treatment for childhood cancer. Ment Retard Dev Disabil Res Rev 12(3):184 191

53. Pierson C, Waite E, Pyykkonen B (2016) A meta-analysis of the neuropsychological effects of chemotherapy in the treatment of childhood cancer. Pediatr Blood Cancer 63(11):1998-2003

54. Kunin-Batson A, Kadan-Lottick N, Neglia JP (2014) The contribution of neurocognitive functioning to quality of life after childhood acute lymphoblastic leukemia. Psychooncology. 23(6):692-699

55. Ehrhardt MJ, Mulrooney DA, Li C, Baassiri MJ, Bjornard K, Sandlund JT, Brinkman TM, Huang IC, Srivastava DK, Ness KK, Robison LL, Hudson MM, Krull KR (2018) Neurocognitive, psychosocial, and quality-of-life outcomes in adult survivors of childhood non-Hodgkin lymphoma. Cancer. 124(2):417-425

56. Tonning Olsson I, Brinkman TM, Wang M, Ehrhardt MJ, Banerjee P, Mulrooney DA, Huang IC, Ness KK, Bishop MW, Srivastava D, Robison LL, Hudson MM, Krull KR (2020) Neurocognitive and psychosocial outcomes in adult survivors of childhood soft-tissue sarcoma: a report from the St. Jude Lifetime Cohort Cancer 126(7): $1576-1584$

57. Scholten L, Willemen AM, Last BF, Maurice-Stam H, van Dijk EM, Ensink E, Zandbelt N, van der Hoop-Mooij A, Schuengel C, Grootenhuis MA (2013) Efficacy of psychosocial group intervention for children with chronic illness and their parents. Pediatrics. 131(4):e1196-e1203

58. Kok JL, Teepen JC, van Leeuwen FE, Tissing WJE, Neggers S, van der Pal HJ et al (2019) Risk of benign meningioma after childhood cancer in the DCOG-LATER cohort: contributions of radiation dose, exposed cranial volume, and age. Neuro-Oncology 21(3): 392-403

Publisher's note Springer Nature remains neutral with regard to jurisdictional claims in published maps and institutional affiliations. 